\title{
An Empirical Study on Digital Media Technology in Film and Television Animation Design
}

\author{
Renfeng Jiang, ${ }^{1}$ Li Wang $\mathbb{D}^{1},{ }^{1}$ and Sang-Bing Tsai $\mathbb{C}^{2}$ \\ ${ }^{1}$ Hebei Academy of Fine Arts, Shijiazhuang, Hebei 050700, China \\ ${ }^{2}$ Regional Green Economy Development Research Center, School of Business, Wuyi University, Nanping, China
}

Correspondence should be addressed to Li Wang; wangli12021@126.com

Received 30 September 2021; Revised 21 October 2021; Accepted 29 October 2021; Published 29 January 2022

Academic Editor: Jiayi Ma

Copyright (C) 2022 Renfeng Jiang et al. This is an open access article distributed under the Creative Commons Attribution License, which permits unrestricted use, distribution, and reproduction in any medium, provided the original work is properly cited.

Computer art and design of digital media technology as a typical cross-technology, combined with graphic images of modern multimedia technology, can show three-dimensional art content and animation design and production of natural affinity; therefore, the digital media technology is introduced into modern animation design and production and is an innovative design concept and method, optimizing the creation efficiency of basic requirements. The reform and innovation of animation design and production are the requirement of the development of The Times. The application of digital media technology in animation design and production is conducive to promoting the development of the animation industry. Animation is human's pursuit of light and shadow. Based on the analysis of the characteristics of digital media, the architecture of the digital media animation system is designed, and the functions of system modules are expounded. Based on the large scale and high efficiency of digital media technology, the framework structure of the animation design system is constructed. Driven by the two-way technology and application, digital media technology is innovatively applied, and three-dimensional animation design and virtual simulation technology are integrated, so as to promote the technological upgrading of animation creation and improve its technical content and level. Through the corresponding test of the system, it is determined that the system can run normally and stably. The digital new media technology is introduced into the design and production of film and television animation to promote the digital development of animation design and production.

\section{Introduction}

With the development of media technology, the current film has made great breakthroughs in sound, production, picture, colour, and other aspects with the use of digital technology, which has changed a lot from the traditional film. With the support of digital media technology, movies now have a good opportunity for sustainability. Network information enriches people's information transmission mode and media form, improves the communication mode between people, and is a major change in the human communication mode [1]. Technological change is indispensable in the transformation of the information dissemination mode. From the beginning of word of mouth to the current network communication, it benefits from the development of media technology. In the process of media development, the media gradually digitizes. Digital media mainly includes digital information, such as text, image, and sound. Digital media can process, record, and transmit words, pictures, images, and sounds digitally. There are two main forms of word media: one is the traditional media converted into traditional forms after digitization. There is also a form that did not exist until the advent of digitalization [2]. Digital media technology is evolving, and as digital media technology evolves, so are the types of digital media, which leads to the creation of mobile digital media.

Digital media is a kind of communication media encoded in the digital form; its essence is to reflect the existence of some kind of digitalization and virtualization [3]. In the era of the collision of industrial civilization and future digital civilization, information technology represented by digital technology and the internet is having a 
tremendous impact on people's lives. The development of digital media has transformed our information sources from traditional media to digital mobile internet media. The innovation of thought, technology, knowledge, and concept has endowed cartoon and other traditional art with richer content and form of expression, thus evolving new art forms, new creation modes, and creation characteristics. The virtual characteristics of digital media are mainly reflected in the aspects of network and software media. By explaining the characteristics of digital media technology, Dahya analyzed the influence of digital media on movies and then discussed the specific application of digital media in movies [4]. Ma et al. comprehensively studied the application of 3D technology in film and television animation design, analyzed the creation process and specific process of midterm production, and analyzed the production steps of character animation production, key issues of animation production, and the production of character walking motion [5]. Aiqing et al. combined artistic spirit and high-tech means to present an art form in the form of digital media [6]. Holroyd analyzed the application characteristics of immersion theory in 3D projection animation in detail and studied and expounded from the aspects of breaking through traditional artistic expression, the relationship between art and technology of 3D projection animation, the influence of different spatial environments on the application of immersion theory, and value analysis [7]. As the digital media environment is a kind of emerging art, Rachmadtullah and Ms pointed out that the social form of "hardware" of the traditional media is slowly transformed into digital media "software form"; this does not have the physical form of material, effectively promotes the media, has a historic change, and even connects the electronic world and the real world, so as to construct a new social information environment [8]. This virtual feature not only affects the form of media, makes people feel dependent, and changes their social behaviours but also is one of the important symbols of the digital media era when the society enters the survival mode of the network.

With the update of the mobile information system and the upgrade of technology, the digital and artistic aspects are combined to carry out deep and extensive circulation and diffusion on various media. It is not limited and guided by media and other factors, and it is not limited and spatialtemporal. Everyone can become the source of communication. Its scope of influence and propagation speed will also be infinitely expanded under the action of the growing population base [9]. The development of the history of animation is actually the continuous exploration of light and shadow by human beings. The working principle of the lantern is similar to that of the magic slide lantern. The light of the candle is projected onto the lamp screen, and the content on the drawing paper is also synchronized with the change of the paper, which is lifelike. Whether magic slide lantern, lantern, or shadow play, although the principles and effects are different, they all reflect the pursuit of light and shadow. For art, digitization means a double revolution in both technology and communication. Interactivity is the most distinctive characteristic of digital media, which changes the one-way communication form of information in the traditional media era and forms an interactive relationship between communicators and audience. This interaction is not limited to between people, the audience can watch the connection behaviour, such as by touch, intelligence, and works of art, to interact to obtain a unique experience, and the feedback data will also be back to the media centre of information, so as to realize the two-way interaction of information as well as the spread and communication of multidimensions.

\section{Theoretical Knowledge of Digital Media}

2.1. Characteristics of Digital Media Technology. Digital media art is characterized by diversity, efficiency, popularization of art, and unbounded communication, which can better integrate the previously related media with film and television to achieve better broadcast effect [10]. Digital media technology will be a good combination of media and film and television; the production and broadcast of the film presented a good effect. According to the characteristics of digital media, flexible use of digital media technology to promote the development of films is one of the future trends of film development. Digital media technology is an abstract entity, based on computer media technology information analysis and processing, to achieve three-dimensional presentation technology. The integration of physical media and computer technology is a comprehensive technology type for digital audio and video, film creation, virtual reality, and other media art forms. Artistic creation, modelling design, technical language, and visual expression in any field are inseparable from digital media technology, and the combination of music, dance, painting, and other art forms will create more colourful artistic modes.

The early films were made and broadcasted in a simple and visually bland way. Performance art background, sound and other lack of a certain artistic effect, the introduction of three-dimensional virtual technology in film production, so that the atmosphere of the scene in the film and the use of virtual technology, videos, and pictures, to a certain extent, highlight the effect [11]. It not only makes the film achieve artistic effect but also presents the film to the audience in a diversified way so that the audience can feel the film from various aspects to achieve the effect of visual enjoyment, so as to be recognized by the audience. In the early film production, the design of any action and the arrangement of any scene required manpower, material resources, and a lot of time, which not only raised the production cost but also made it difficult to achieve the production of some scenes. Nowadays, the introduction of digital media can efficiently switch film background, using digital technology, to virtual background buildings, etc.

2.2. Design and Production of Animation. Special effects are used in a wide range of fields, such as film and television, games, advertising, and even medical and military fields. The addition of special effect art not only reduces the production cost but also, most importantly, enhances the ornamental 
value, greatly enhancing the sensory effect and making things more vivid and convincing. It can be said that all digital visual performances are inseparable from special effect art, which shows its importance.

3D animation is a new technology which comes into being under the rapid development of digital age. Designers can freely create works with three-dimensional space and 360-degree viewing through computer technology according to their own will and can give them the ability to move according to the trajectory [13]. 3D animation special effect art refers to the application of special effect art in $3 \mathrm{D}$ animation. 3D animation can be more expressive through the packaging of special effect art, enhance the visual impact, and enhance the value of art appreciation. Special effect art has broken the design pattern of previous digital media advertising and enhanced its visual effect and artistic performance effect. The application of special effect art provides unlimited imagination and design space for digital media advertising designers [14]. The birth of digital media cannot be separated from the participation of special effect art, and special effect art can make it have more beautiful scenes, beyond the imagination of designers, can create the original scenery, and provide designers with a very large creative space, using powerful special effect art to infect the hearts of people. There are many elements in special effect art, such as light, shadow, object, space, animation, and various elements that exist and do not exist in real life. Only through the cooperation of different lens art can it be called a complete special effect art work.

\subsection{Digital Media Technology and Animation Design and} Production Integration. Digital media technology can promote animation design and production in the application and development in many areas and improve the commercial value of animation industry [15]. In the era of new media, film and television art creation, game special effect design, animation image modelling, and so on, are inseparable from animation design and production; especially, with the in-depth development of the animation industry, $3 \mathrm{D}$ animation image has been widely used in many fields, the scope of application is expanding and also promotes the mass development of animation design and production. Traditional manual drawing of animation images and role modelling can no longer meet the requirements of the new era, so the development of digital media technology provides support for large-scale and efficient creation of animation design and production [16]. Digital media technology integrates 3ds Max, Photoshop, Flash, and other animation design and production software. Designers can make online design with the help of computers, import the design drawing library into 3ds Max for character modelling, and modify and process animation images through Photoshop. Flash software is used to configure sound effects for animation characters, and the effect of animation scenes can be previewed in the virtual environment created by virtual reality technology, so as to realize three-dimensional presentation of animation characters.

The basic goal of animation design and creation is to achieve application to obtain commercial value, and the quality of design at this time is the basis and premise of seeking commercial value. The traditional design technology in hand-painted animation more showed the image of the connotation and the creation of artistic conception, was based on paper media or television publicity and promotion, rendering the animation effect of dull and boring and lack of originality, fundamentally restricted the animation design and production quality and effect, and attracted people's attention, not to mention the commercial application and promotion [17]. In the new media era, the application and promotion of digital media technology provide life cycle support for animation design and creation. Preproduction can use 3D, Flash, VR, and other software and technologies to give animation design and production the texture of $3 \mathrm{D}$ animation so that animation characters are more vivid.

2.4. Data Processing. The core idea of the $k$-means algorithm is to minimize the Euclidean distance between all samples and the cluster centre [18]. In the scenario of age analysis of animation users, the number of cluster centres $f$ output by $k$ means algorithm is the number of age segments, $f=6$. The specific steps of using $k$-means algorithm to realize the age analysis of animation users are as follows:

$$
d_{j i}=\left\|x_{j}-y_{i}\right\| .
$$

Select the cluster centre nearest to $x_{j}$ as the cluster label $A$ of the sample, and the formula is

$$
A=\arg \sum_{i=1} \min d_{j i} .
$$

At the same time, the sample was added to cluster $A$, as shown in the following formula:

$$
C_{A}=C_{A} U\left\{x_{j}+1\right\} .
$$

According to formula (3), the new cluster centre of each cluster is calculated to obtain a new cluster centre set.

$$
\eta_{i}^{\prime}=\frac{1}{\left|C_{i}\right|} \sum_{x \in c_{i}} x+1
$$

The distortion function $F$ of the model is the sum of squares of Euclidean distances from all samples to their corresponding cluster centre.

$$
F=\sum_{j=1}^{m}\left\|x_{j}-A\right\| .
$$

Using the new cluster centre, repeat formulas (4)-(5) until the function converges. 


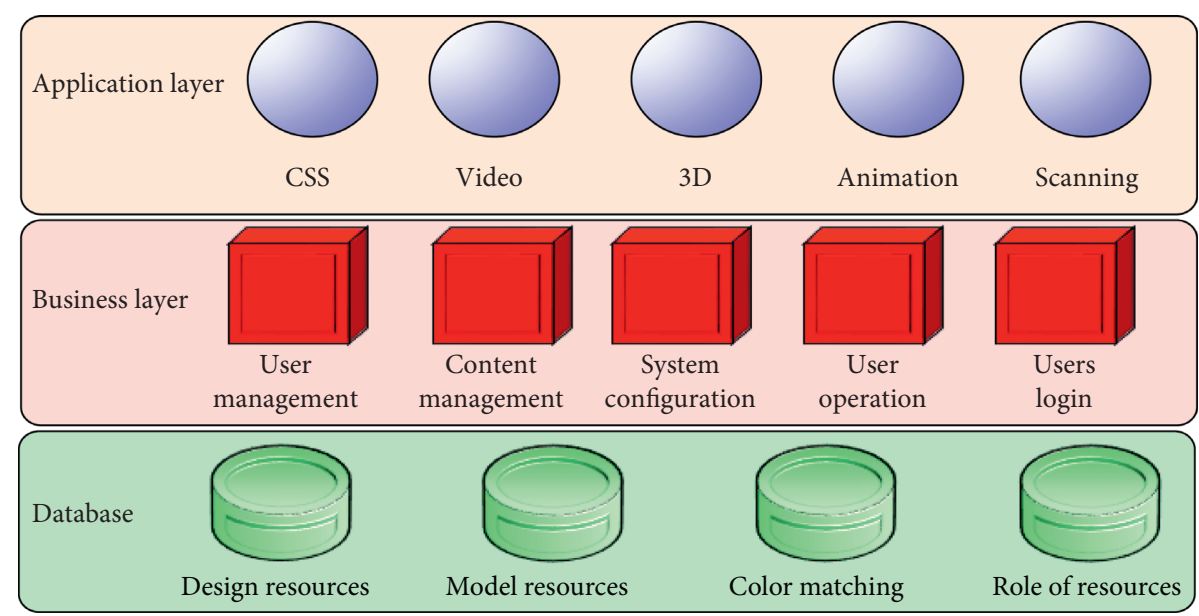

FIgURE 1: Application of the digital media animation system architecture diagram.

\section{Design of the Animation System with Digital Media}

3.1. Systematic Architecture Design. In the development process of the whole system, the overall architecture adopts the B/S structure. That is, the user's operation interface in the whole system is displayed through the browser side, and the middle layer realizes the data information interaction between the browser side operation interface and the system background database through the web server. This results in a so-called three-tier architecture-presentation layer, business layer, and database layer [19]. This three-tier structure mode has very distinct advantages and can greatly simplify the maintenance of the system operation; the three-tier structure also makes the server run more quickly, reduce the server running pressure, and increase the interaction of data. The system architecture of the digital media animation system is shown in Figure 1.

The presentation layer is a layer where users can directly operate. Users can see the operating interface of the system and issue operation instructions [20,21]. Generally speaking, the presentation layer is a relatively friendly interactive interface greatly optimizing the presentation layer and making the system interface very simple and friendly; users can have a relatively good operation experience. The business logic layer is the middle layer between the presentation layer and the data layer. It is mainly responsible for the corresponding processing of the user's request and the immediate feedback to the user. At the same time, it can also issue the corresponding instructions to the database. The data layer is the database of the system, which contains all the data generated during the operation of the system. At the same time, according to the instructions sent by the business layer, the data can be added, deleted, modified, and checked correspondingly [22-24].

It can be seen from the system architecture diagram that the system consists of three parts: presentation layer, business layer, and database layer. This three-layer hierarchical structure is independent of each other, but can be linked through the transmission of instructions. The operation of one layer does not affect the normal operation of the other layers, which is very suitable for software team development.

3.2. Diffuse Model Frame Structure. The software system uses object-oriented technology, $\mathrm{C}++$ language under Windows, model grid processing function library, and numerical calculation function library and proposes and realizes the interactive simulation system which takes user experience as the core. It mainly includes the following aspects: the control of the main operating system to the $3 \mathrm{D}$ scanning role system, the control of the operator is to realize the scene transformation through the operation of the camera; user interface system of the 3D scanning character system: mainly controls the progress of operation, character selection, character design, texture design, and character preservation process; creating, dragging, modifying, and assembling $3 \mathrm{D}$ models and mapping and attaching materials to models. The frame structure of the animation model is shown in Figure 2.

3.3. System Function Module Design. According to the analysis of the functional requirements of the system, the animation system is composed of six modules, which are resource upload modules for members to upload animation resources, the user management module for members to manage personal information, the resource management module where the administrator manages the animation resources in the entire animation system, an approval management module for administrators to review and manage animation resources uploaded by users, the news management module where the administrator can release, modify, and delete animation news, and the permission management module for administrators to manage other subadministrators. According to function division, the overall function of the animation system is roughly divided into four parts, and the corresponding structure diagram is shown in Figure 3.

In the system, the user resource upload module is responsible for the user's operations on resource upload, including uploading resources, viewing the status of uploaded 
resources, viewing successfully uploaded resources, and deleting uploaded resources. When users upload animation resources, the administrator can view the uploaded animation resources and detailed information in the audit function module. The administrator can carry out audit processing. If the resource is approved, it is allowed to be uploaded into the database and displayed in the system page immediately. The resource uploaded by the user changes from the status of pending audit to the status of approved audit in my works. The user-related user management module is mainly responsible for the management and operation of users' personal information. Users register as members, fill in relevant personal information, and send the verification code to users' mobile phones through the server; users must fill in the received verification code to register successfully. After successful registration, users can $\log$ in to the system to enjoy more advanced services. After successful login, users can query their basic personal information in the membership service and can modify personal information at any time; the database will synchronize the personal information modified by users.

In the system, the resource management module of the administrator is mainly responsible for the administrator's various management operations of animation resources. These operations include the administrator uploading resources to the background database of the animation system, querying the saved animation resources, modifying the properties of the animation resources, deleting the animation resources, and classifying the animation resources. During the process of uploading resources, the administrator can modify the attribute labels of the animation resources and display them in different categories. When there are more and more animation resources in the database, it is quite difficult for the administrator to find a certain resource through traversal. At this time, it is necessary to accurately locate resource information through fuzzy search of resources. The search and query function can satisfy the administrator's management of animation resources.

Through the previous demand analysis, users can assist to upload all kinds of animation resources after registering as members, but the animation resources uploaded by members have a wide range of sources; if directly stored in the database, they cannot ensure the unity of the database and the security of the system. Therefore, the administrator must approve the operation to determine whether the resource can be input into the database. After members upload animation resources, these resources will be passed into the background data table. Administrators can immediately view the resources uploaded by users in the approval module of the background and approve them. If you select the "through" button, the resource will be recorded into the animation resource database and can be managed by the administrator in the resource management module. If you select "Reject," the resource will not be recorded into the database. When too many resource files are uploaded at the same time, the administrator can also use the fuzzy search function to query related resources and priority resources.
3.4. The Logical Data Structure of the System. The key technology of the 3D scanning character modelling design system requires processing of the scanned digital model information, with the purpose of constructing characteristics close to the character modelling and optimizing the point cloud model to meet the use requirements of the later animation or film [21]. The system consists of 3D scanning data acquisition, data point cloud preprocessing, role model reconstruction, decorative database invocation, and $3 \mathrm{D}$ display.

After the data and information related to the role model are collected by the scanner, the role model can be classified into three categories: realism uses different input ports of figure painting and freehand painting. After receiving the data, it preprocesses the data according to the proportion, data form, physical change angle, joint freedom, and other settings of such role models. Otherwise, it is easy to cause differences caused by errors in the data collection process and model modelling. According to the characters of different types of point cloud model feature points and feature sizes' information via the data pretreatment, through the layers of cross section with this kind of role model match and a role model of each layer type value point information, choose a different model reconstruction method, and then call the database model design optimization of the reconstruction model; you can add some accessories and details, and complete the optimization design of the role model. The four-edge mesh processing was carried out for the surfacegenerating points of the role model. After calculating the normal vector and other information for each point, the role model was displayed. Figure 4 is the flowchart of the role model system. The system is optimized and designed according to different types of role characteristics. See Figure 4 .

\section{Realization of the Digital Media Animation System}

4.1. Choice of the Development Environment. The animation system in this paper uses the Java language as the main development language, the development kit necessary for the development of Java is JDK 1.9, and the development tool is selected, the more convenient MyEclipse CI 2017, which is the current relatively new version. The server of the system chooses the latest version of Tomcat 9.0, and the database chooses the most commonly used MySQL database. The operating system used in the whole development process is the 64-bit Microsoft Windows 10 flagship edition.

4.2. Testing Process. This part will select the function of user registration, member password modification, member upload animation resources, administrator review animation resources, and at the end of the main interface of animation system operation. To register, users need to fill in relevant personal information and send the verification code to the user's mobile phone through the system for verification. Registration is successful only after verification. 


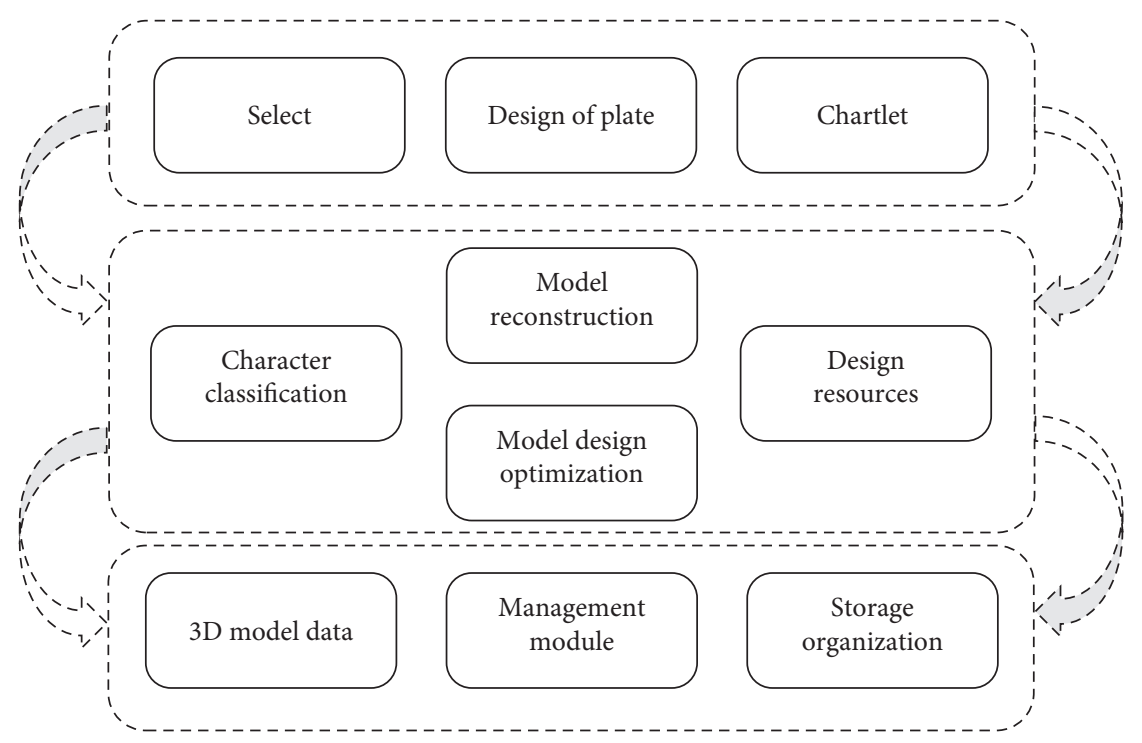

Figure 2: Frame structure of the animation model.

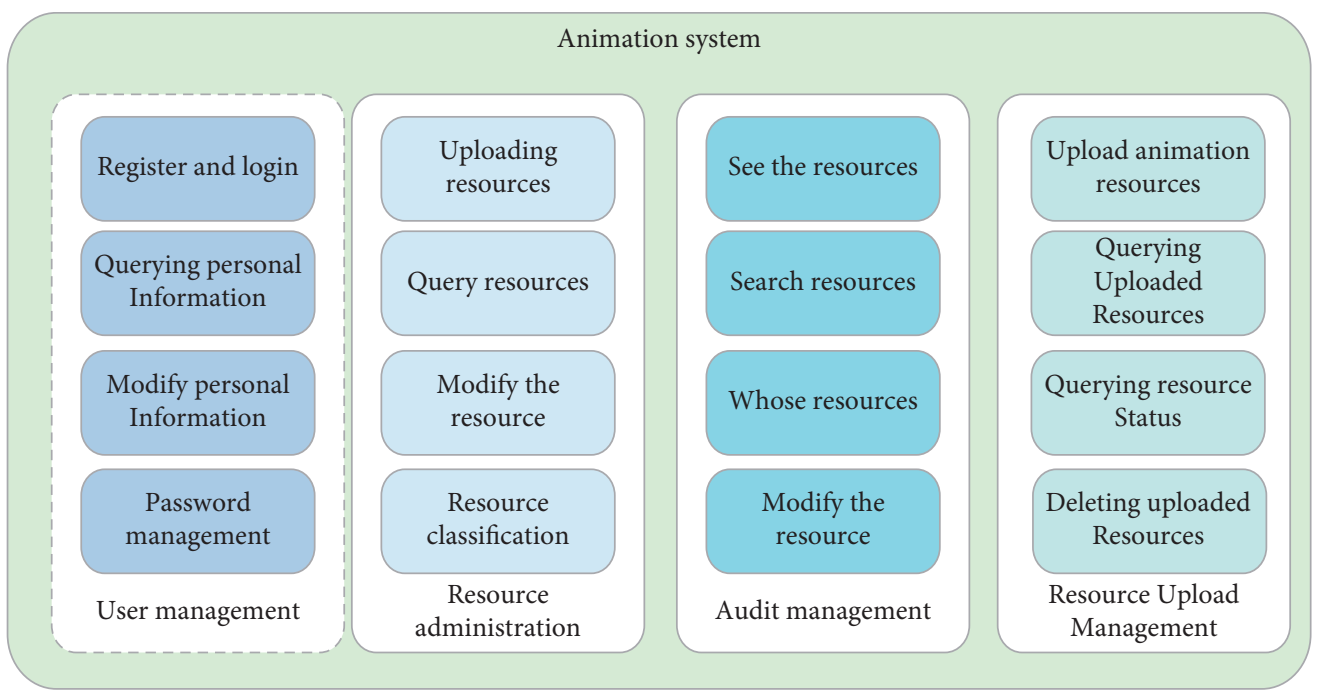

FIGURE 3: System function module structure diagram.

Members can change their passwords here by clicking on the member benefits option in the upper right corner and selecting security settings. Enter the old password, new password, and confirm password. If the old password is different from the old password, a message is displayed indicating that the password is incorrect, and the password cannot be changed. If the old password is the same as the old password, the new password must be the same as the confirmed password. Otherwise, the new password cannot be changed. Users who have registered as members can upload their videos here by clicking on the member privileges option in the upper right corner and selecting my videos. Click the upload function to pop up the upload interface and upload procedure call method; the uploaded video can view the current audit status. The administrator can perform management operations only after logging in to the background system. Log in to the main screen. The administrator needs to check the uploaded resources. If you click "Pass," the resources will be uploaded to the system database; if you click "Reject," the resources will not be uploaded.

Performance testing is to collect and analyze the performance data of the system under different operating conditions by using automated testing tools under the 


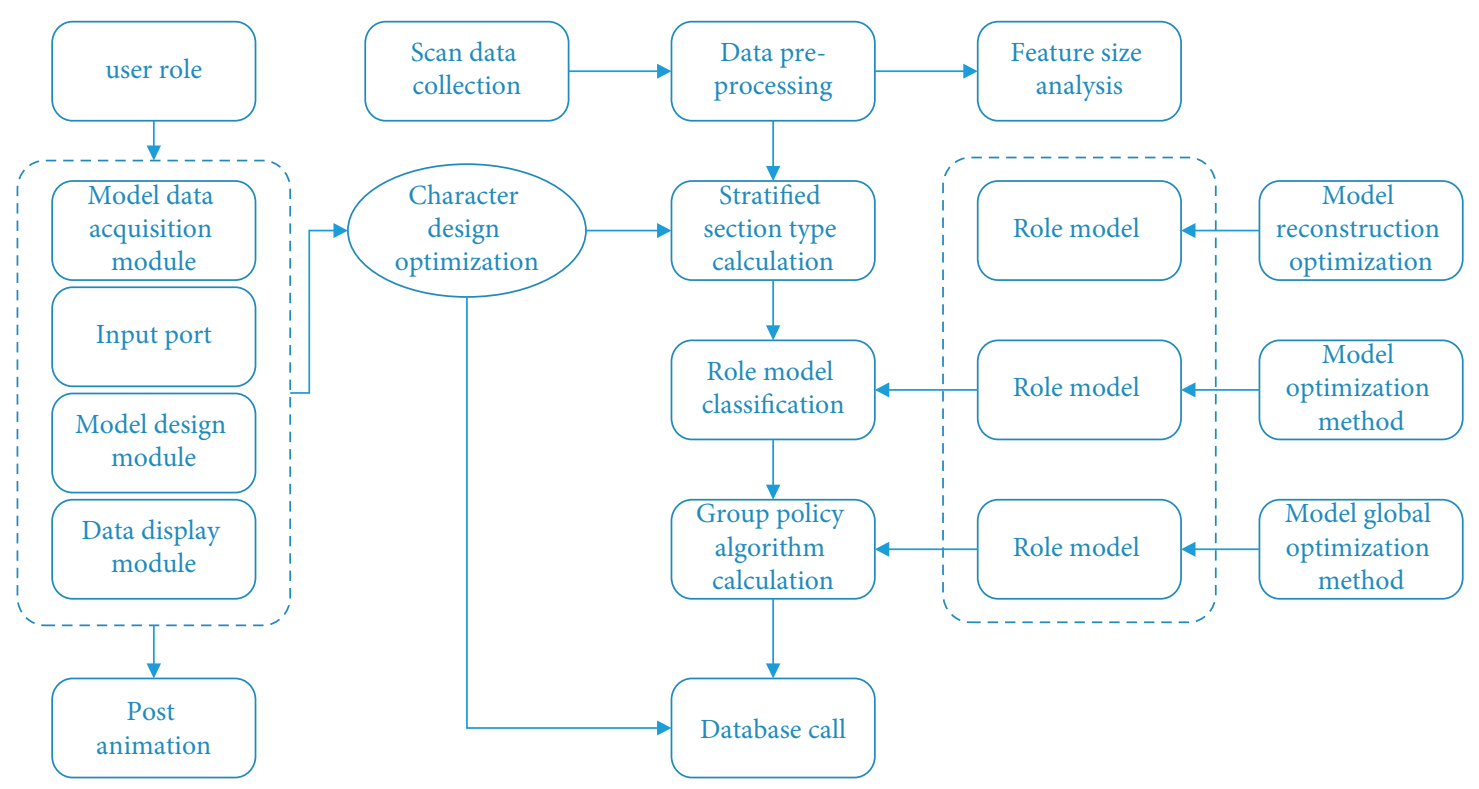

FIgURE 4: Role model system flowchart.

normal operation of the system. The specific test steps are as follows: (1) open the login page to be tested; (2) use network to record login operations; (3) enter the administrator account and password to $\log$ in; (4) view recorded network data and analyze system performance.

4.3. System Function Module Test. Functional testing is to carry out corresponding tests for each functional module of the system. By designing test cases, various situations triggered by the function are tested, so as to test whether the functional module meets the expected design and whether it can give feedback to different test cases correctly. The functional test of the system module is shown in Figure 5.

As can be seen from the figure, $98.29 \%$ of member information is stored in the user table, the realization rate of member animation resource upload is $95.45 \%$, the administrator audit function module is $89.32 \%$, the passing rate of the resource audit function test is $98.34 \%$, and the passing rate of the overall system operation test is $92.76 \%$. The test results are consistent with the expected test results. The functional modules of the animation system work well and meet the functional requirements designed in advance.

4.4. Performance Test. Performance testing is to collect and analyze the performance data of the system under different operating conditions by using automated testing tools under the normal operation of the system. Here, the processing time of the system is selected for testing. The home page of the login system is selected as the test case, and the network in the developer tool of the browser is selected to test the response time of the website. The network button records all kinds of request resource information obtained from the initiation of web page request to the background analysis of the HTTP request, mainly including resource types. The processing time of the system is selected for testing. The login system home page is selected as the test case, and the response time of the test website is shown in Figure 6.

As can be seen from the figure, the design of the member management module, resource upload module, resource management module, and resource audit module has been concreted. The test results all meet the functional design of the system. The analysis of test data shows that the system has good processing speed. The response time of each module is extremely short, and the longest response time is $90 \mathrm{~ms}$ for the authentication of account and password. This shows that the system has a good response processing speed.

Interface design and implementation of the system platform, system design, information design, and logical data structure to the point of view of art present a grouping strategy, a new method for the optimization of the animation role model according to the three types of the group role model, using the solving strategy of divide and conquer and $3 \mathrm{D}$ scanning character modelling design system scheme. The design and implementation of the 3D scanning character modelling design system were tested and evaluated to evaluate users' experience of the design system, conduct the test form of the actual operation of the design system, sort out the information of five representative effective users, and score the 3D scanning character modelling design system. Related information and user test scoring results are shown in Figure 7.

As can be seen from the test score chart, users are satisfied with the design practice of the 3D scanning character modelling design system. The system design theme is clear, the operation process is reasonable, and users have emotional experience of creating their own character animation design. 


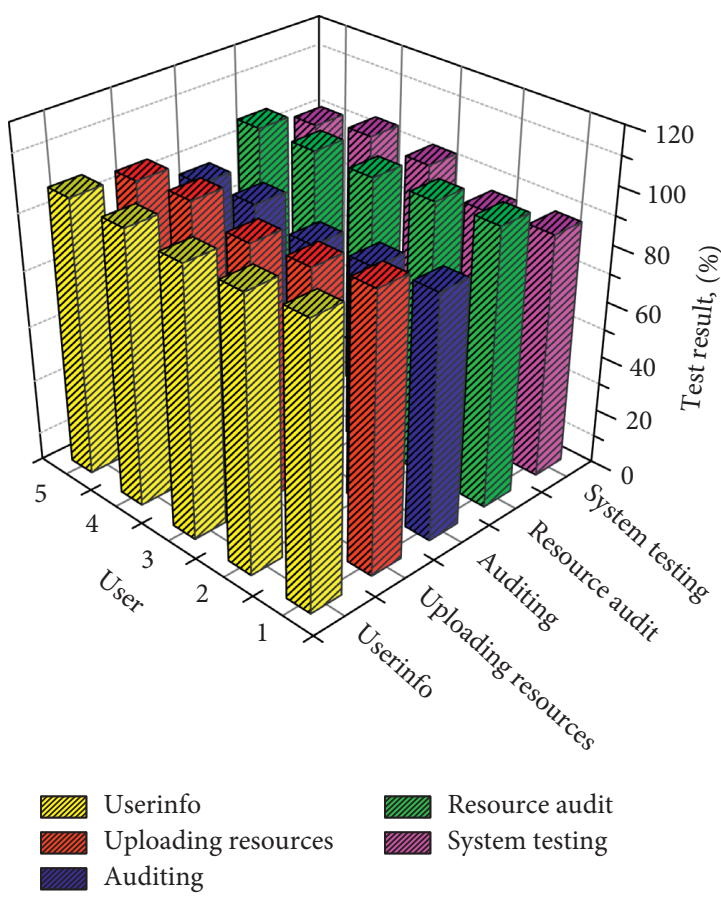

Figure 5: System module function test diagram.
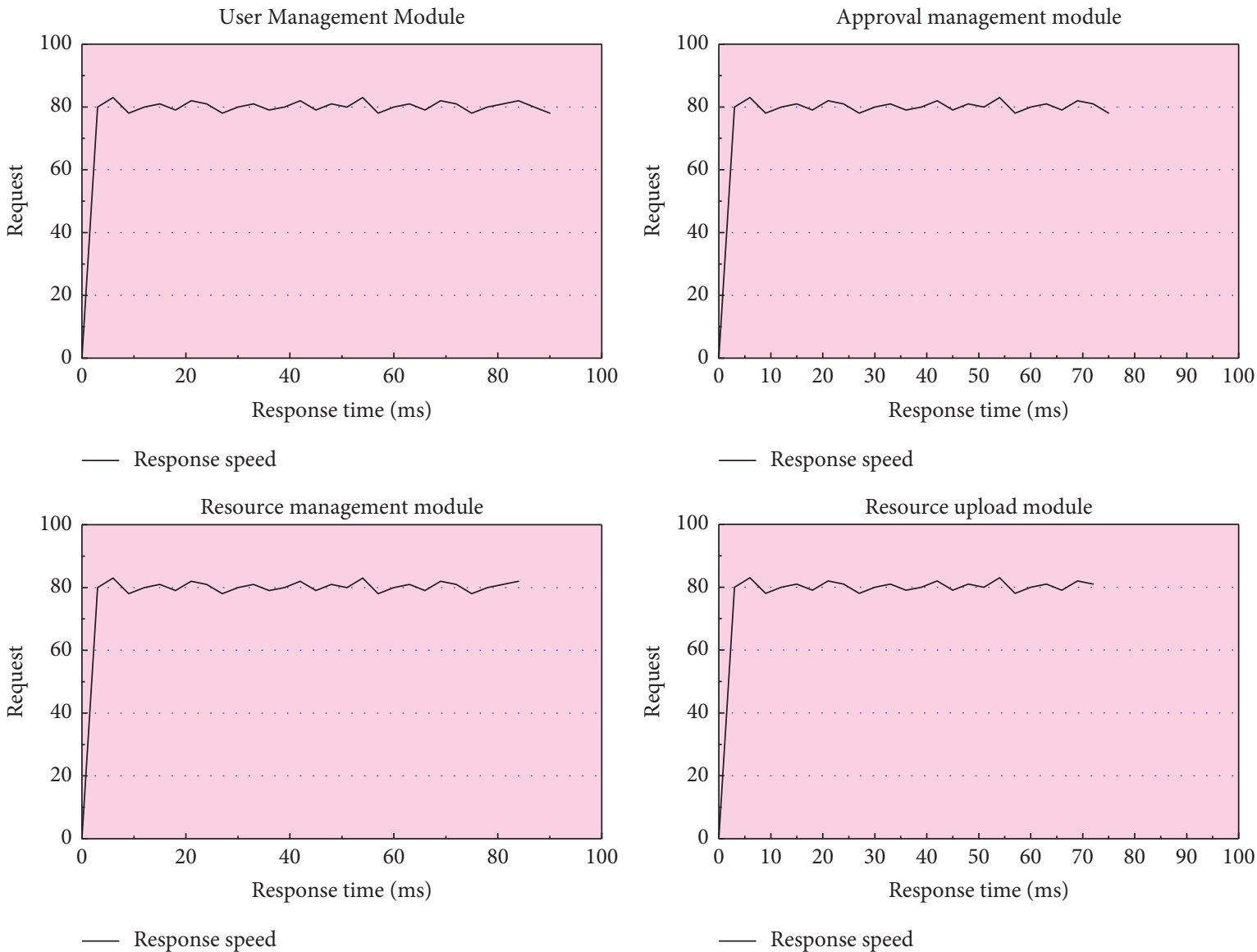

Figure 6: The response time test diagram of each module of the website. 


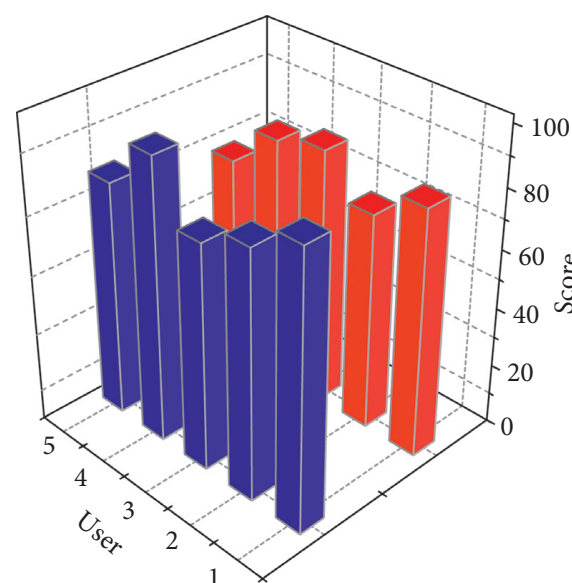

Process planning

Goal-oriented

Operational test score diagram

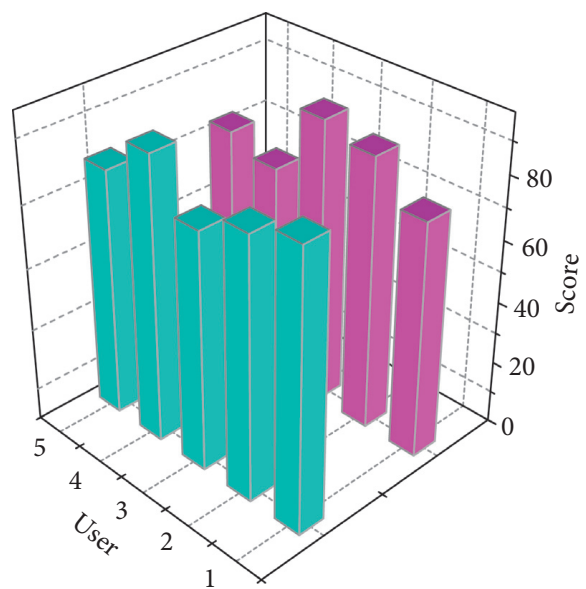

Subject

Function

Functional test score diagram

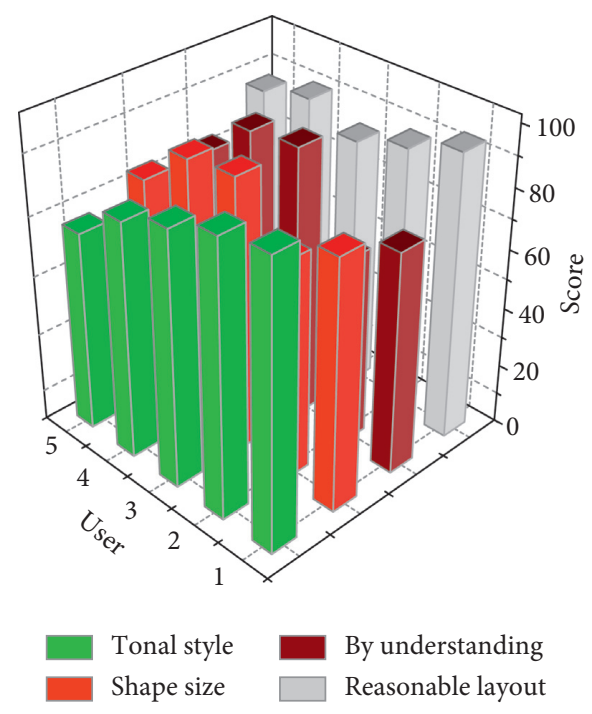

Visual style test score chart

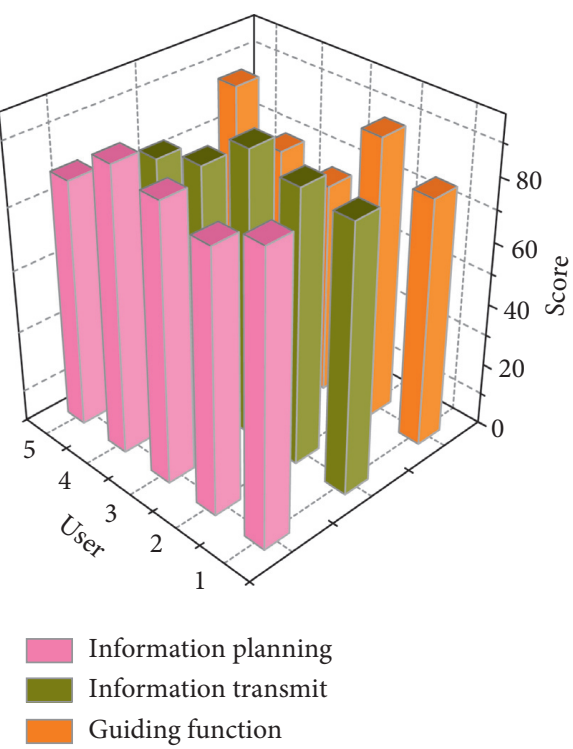

Content test score diagram

Figure 7: Statistical view of user test score results.

\section{Conclusion}

Digital media technology is a comprehensive technology spanning the humanities, art, and science, based on media technology, interactive design language, and computer vision images, to present the animation art creation content, and animation design and production have a lot of compatibility. Based on the analysis of the characteristics of digital media, the architecture of the digital media animation system is designed, and the function of the system module is expounded. The function modules of the animation system are designed in detail, and the function and performance tests of the system are carried out. The response time of each module is extremely short, and the longest response time is $90 \mathrm{~ms}$ for the verification of the account password. The system has good response processing speed. The system design theme is clear, the operation process is arranged reasonably, the layout is reasonable, the picture and text are well illustrated, the main information is conveyed clearly and effectively in the content, and the progress bar has played a very good, prompt, and guidance role in the design. The use of digital media technology in animation design and production has brought new development opportunities for the development of the animation industry and effectively realized the economic benefits of animation products. The functions of the system have roughly met the basic functional requirements put forward by users, but in the development process, due to many uncontrollable factors such as limited personal technology level. Virtualization technology security research and laboratory information security are the key and difficult points of laboratory construction; in the following work, we will carry out information security research. 


\section{Data Availability}

The data used to support the findings of this study are included within the article.

\section{Conflicts of Interest}

The authors declare that there are no conflicts of interest.

\section{Acknowledgments}

Innovative Entrepreneurship Practice Conditions Construction Project, Hebei Academy of Fine Arts Animation College Platform Practice Teaching Base Construction 2017 CXCY238.

\section{References}

[1] M. Keane, "China's digital media industries and the challenge of overseas markets," Journal of Chinese Cinemas, vol. 13, no. 3, pp. 244-256, 2019.

[2] U. Caspary, "Digital media as ornament in contemporary architecture facades: its historical dimension," The Screen Media Reader: Culture, Theory, Practice, vol. 2017, pp. 43-152, 2017.

[3] W. Wiana, "Application design of interactive multimedia development based motion graphic on making fashion design learning in digital format," International Journal of Scientific \& Technology Research, vol. 6, no. 5, pp. 102-108, 2017.

[4] N. Dahya, "Critical perspectives on youth digital media production: "voice" and representation in educational contexts," Learning, Media and Technology, vol. 42, no. 1, pp. 100-111, 2017.

[5] L. Ma, C. Qian, Z. Liu, and Y. Zhu, "Exploring the innovation system of the animation industry: case study of a Chinese company," Sustainability, vol. 10, no. 9, p. 3213, 2018.

[6] W. Aiqing, W. Xitong, and H. Fengwu, "Research on the digital multimedia technology and urban landscape design based on multimedia art perspective," International Journal of Multimedia and Ubiquitous Engineering, vol. 11, no. 10, pp. 371-380, 2016.

[7] C. Holroyd, "Digital content promotion in South East Asia: government strategies for a new economic sector," Journal of Asian Public Policy, vol. 12, no. 1, pp. 15-33, 2019.

[8] R. Rachmadtullah, Z. Ms, and M. Syarif Sumantri, "Development of computer-based interactive multimedia: study on learning in elementary education," International Journal of Engineering \& Technology, vol. 7, no. 4, pp. 2035-2038, 2018.

[9] Z. Liu, "The impact of government policy on macro dynamic innovation of the creative industries: studies of the UK's and China's animation sectors," Journal of Open Innovation: Technology, Market, and Complexity, vol. 7, no. 3, p. 168, 2021.

[10] Y. Shi, C. Feng, and Y. Shen, "Research on graphic design based on digital media," Acta Technica CSAV, vol. 62, no. 1, pp. 391-400, 2017.

[11] S. Nan, "Multimedia image technology and computer aided manufacturing engineering analysis," IOP Conference Series: Materials Science and Engineering, vol. 317, no. 1, p. 012046, 2018.

[12] R. Bridgstock, "Educating for digital futures: what the learning strategies of digital media professionals can teach higher education," Innovations in Education and Teaching International, vol. 53, no. 3, pp. 306-315, 2016.
[13] R. M. Patton and M. L. Buffington, "Keeping up with our students: the evolution of technology and standards in art education," Arts Education Policy Review, vol. 117, no. 3, pp. 1-9, 2016.

[14] D. Lupton, "Digital media and body weight, shape, and size: an introduction and review," Fat Studies, vol. 6, no. 2, pp. 119-134, 2017.

[15] M. K. Afify, "The effect of the difference between infographic designing types (static vs animated) on developing visual learning designing skills and recognition of its elements and principles," International Journal of Emerging Technologies in Learning, vol. 13, no. 9, pp. 204-223, 2018.

[16] A. Levinson and B. Barrod, "Latino immigrant families learning with digital media across settings and generations," Digital Education Review, vol. 33, pp. 150-169, 2018.

[17] J. Mateer, "Directing for cinematic virtual reality: how the traditional film director's craft applies to immersive environments and notions of presence," Journal of Media Practice, vol. 18, no. 1, pp. 14-25, 2017.

[18] R. Coleman, "Theorizing the present: digital media, preemergence and infra-structures of feeling," Cultural Studies, vol. 32, no. 4, pp. 600-622, 2018.

[19] A. M. Leach, "Digital media production to support literacy for secondary students with diverse learning abilities," Journal of Media Literacy Education, vol. 9, no. 2, pp. 30-44, 2017.

[20] W. Andriyan and V. Anesti, "Visual audio communication design on the role of information technology on student life style of universitas raharja," ADI Journal on Recent Innovation, vol. 2, no. 1, pp. 15-24, 2020.

[21] J. Liu, "Application of digital media technology in animation design and production," Journal of Physics: Conference Series, vol. 1486, p. 42035, 2020.

[22] S. Deng, Y. Du, and L. Qi, "A web service composition approach based on planning graph and propositional logic," Journal of Organizational and End User Computing, vol. 31, no. 3, pp. 1-16, 2019.

[23] T.-H. Chou, "Exploring relationship quality of user's cloud service," Journal of Organizational and End User Computing, vol. 31, no. 3, pp. 17-36, 2019.

[24] D. N. Kanellopoulos, "Recent progress on QoS scheduling for mobile ad hoc networks," Journal of Organizational and End User Computing, vol. 31, no. 3, pp. 37-66, 2019. 